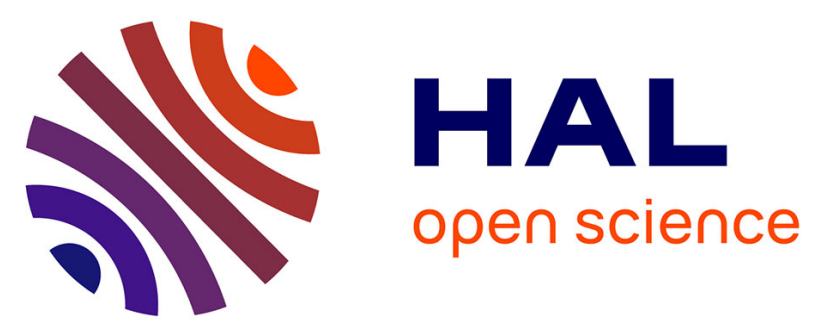

\title{
A review of the developments in nuclear track methodology as published in the proceedings of the International Conference on Nuclear Tracks in Solids from 1990 to 2008
}

\author{
Guillermo Espinosa, Lluis Font, Michel Fromm
}

\section{To cite this version:}

Guillermo Espinosa, Lluis Font, Michel Fromm. A review of the developments in nuclear track methodology as published in the proceedings of the International Conference on Nuclear Tracks in Solids from 1990 to 2008. 25th Int. Conf. on Nuclear Tracks in Solids, Sep 2011, Puebla, Mexico. pp.1-6. hal00821904

\section{HAL Id: hal-00821904 https://hal.science/hal-00821904}

Submitted on 15 May 2013

HAL is a multi-disciplinary open access archive for the deposit and dissemination of scientific research documents, whether they are published or not. The documents may come from teaching and research institutions in France or abroad, or from public or private research centers.
L'archive ouverte pluridisciplinaire HAL, est destinée au dépôt et à la diffusion de documents scientifiques de niveau recherche, publiés ou non, émanant des établissements d'enseignement et de recherche français ou étrangers, des laboratoires publics ou privés. 


\title{
A Review of the Developments in Nuclear Track Methodology as Published in the Proceedings of the International Conference on Nuclear Tracks in Solids from 1990 to 2008
}

\author{
G. Espinosa ${ }^{\mathrm{a}}$, Ll. Font ${ }^{\mathrm{b}}$, M. Fromm ${ }^{\mathrm{c}}$ \\ ${ }^{a}$ Instituto de Física, Universidad Nacional Autónoma de México. \\ Circuito de la Investigación Científica, Ciudad Universitaria, 04510, México, D.F. \\ ${ }^{\mathrm{b}}$ Grup de Física de les Radiacions, Universitat Autònoma de Barcelona, \\ Departament de Física, E-08193 Bellaterra, Spain \\ ${ }^{\mathrm{c}}$ Laboratoire de Chimie Physique et Rayonnements - Alain Chambaudet, UMR CNRS 6249, \\ Université de Franche-Comté, 16 route de Gray, \\ F-25030 Besançon cedex, France
}

*Corresponding author: espinosa@ fisica.unam.mx

Keywords: Nuclear Track; International Conference on Nuclear Tracks in Solids; ICNTS

\begin{abstract}
The aim of this paper is to provide an overview of the developments in nuclear track methodology as published in the proceedings of the last ten meetings of the International Conference on Nuclear Tracks in Solids (ICNTS) from the Marburg (Germany) conference in 1990 to the Bologna (Italy) conference of 2008. Nuclear Tracks Methodology (NTM) examines the effects of the interaction between charged particles and solid materials and presents several desirable characteristics: the detectors can easily be cut into a size appropriate for any application and can be used in locations for which other radiation detectors are not suitable; the etching and reading instrumentation is relatively simple; there is a quasiinsensibility to gamma radiation for reasonable dose exposures (typically $<1 \mathrm{kGy}$ ); after
\end{abstract}


chemical etching the information recorded on the detector material is essentially permanent; and, finally, the system involves relatively low costs. These characteristics have contributed to the importance of NTM for radiation detection in an immense number of applications across a wide range of scientific and technological fields.

This paper reviews the new ideas, topics, materials and applications related to NTM that have been presented over the past ten ICNTS meetings from 1990 to 2008, and analyzes the evolution of various topics. One could argue that the conferences themselves have been an important source of new ideas and applications for the nuclear track research community. Two important observations arise from this review. The first is that the contributions of the past ten international conferences can be conveniently classified into 12 categories. The second is that the number of papers published varied widely from conference to conference. Several factors contributed: the variation in the number of conference participants, the interests of local participants (who account for a disproportionate number of conference participants), the location of the conference, and the appearance of new international conferences devoted to topics similar to those covered by the ICNTS.

\section{Introduction/Scope}

The basic principles describing the slowing down of swift ions as they pass through solidstate materials, the accompanying production of localized physical and chemical modifications, and the observation of such modifications -nuclear tracks- using a chemical process, were presented by Young (1958) and Price and Walker (1961) and described in detail in the book Nuclear Tracks in Solids (Fleischer et al., 1975). The mass and energy of the ionizing particles can be determined by analyzing the track parameters after chemical 
treatment. Very briefly, the number of tracks per square centimeter (the track density) is a function of the source activity, and the track diameter is related to the particle energy. More than 54 years have passed since the publication of the first works on nuclear track formation in solids (Espinosa, 1991; Fleisher, 1991). Furthermore, 21 years separate the $15^{\text {th }}$ International Conference on Nuclear Tracks in Solids in 1990 from the $25^{\text {th }}$ International Conference in 2011. Over this period, the applications of NTM expanded to include the areas of cosmic rays, new materials, nanotechnology, dating, neutron dosimetry, and environmental sciences. NTM now constitutes an essential tool in several of these fields. At the beginning of the 1980s, Tommasino et al. (1980a, 1980b) discovered the electrochemical etching technique, which basically consists of applying high-frequency AC voltage during the chemical etching process. The electric field produces a dielectric breakdown and a magnification of the track, making it visible to the naked eye. This technique has become very popular in neutron and radon studies. Without doubt, the International Conferences on Nuclear Tracks in Solids (and their earlier iterations under different names) have been instrumental in developing and promoting Nuclear Tracks Methodology. A total of 1551 papers were published in the proceedings of the ten conferences that took place between 1990 and 2008 (Brandt et al., 1991; Guo et al., 1993; Perelygin et al., 1995; Ilić et al., 1997; Chambaudet et al., 1999; Ilić et al., 2001; Dwivedi et al., 2003; Fernandez et al., 2005; Guo et al., 2008; d'Errico et al., 2009). 
The names, locations and dates of the 25 conferences that have taken place to date are listed below.

$1^{\text {st }}$ International Colloquium on Corpuscular Photography, Strasbourg, France, 1957.

$2^{\text {nd }}$ International Colloquium on Corpuscular Photography, Montreal, Canada, 1958.

$3^{\text {rd }}$ International Colloquium on Corpuscular Photography, Moscow, USSR, 1960.

$4^{\text {th }}$ International Colloquium on Corpuscular Photography, Munich, Germany, 1962.

$5^{\text {th }}$ International Conference on Nuclear Photography, Geneva, Switzerland, 1964.

$6^{\text {th }}$ International Conference on Nuclear Photography, Florence, Italy, 1966.

$7^{\text {th }}$ Inter. Colloquium on Corpuscular Photography and Visual Solid Detectors, Barcelona, Spain, 1970.

$8^{\text {th }}$ International Conference on Nuclear Photography and Solid State Detectors, Bucharest, Romania, 1972.

$9^{\text {th }}$ International Conference on Solid State Nuclear Track Detectors, Munich, Germany, 1976.

$10^{\text {th }}$ International Conference on Solid State Nuclear Track Detectors, Lyon, France, 1979.

$11^{\text {th }}$ International Conference on Solid State Nuclear Track Detectors, Bristol, UK, 1981.

$12^{\text {th }}$ International Conference on Solid State Nuclear Tracks in Solids, Acapulco, Mexico, 1983.

$13^{\text {th }}$ International Conference on Solid State Nuclear Track Detectors, Rome, Italy, 1985.

$14^{\text {th }}$ International Conference on Solid State Nuclear Track Detectors, Lahore, Pakistan, 1988.

$15^{\text {th }}$ International Conference on Particle Tracks in Solids, Marburg, Germany, 1990.

$16^{\text {th }}$ International Conference on Nuclear Tracks in Solids, Beijing, China, 1992.

$17^{\text {th }}$ International Conference on Nuclear Tracks in Solids, Dubna, Russia, 1994.

$18^{\text {th }}$ International Conference on Nuclear Tracks in Solids, Cairo, Egypt, 1996.

$19^{\text {th }}$ International Conference on Nuclear Tracks in Solids, Besancon, France, 1998.

$20^{\text {th }}$ International Conference on Nuclear Tracks in Solids, Portoroz, Slovenia, 2000.

$21^{\text {st }}$ International Conference on Nuclear Tracks in Solids, New Delhi, India, 2002.

$22^{\text {nd }}$ International Conference on Nuclear Tracks in Solids, Barcelona, Spain, 2004.

$23^{\text {rd }}$ International Conference on Nuclear Tracks in Solids, Beijing, China, 2006.

$24^{\text {th }}$ International Conference on Nuclear Tracks in Solids, Bologna, Italy, 2008.

$25^{\text {th }}$ International Conference on Nuclear Tracks in Solids, Puebla, Mexico, 2011. 
Thanks to the valuable and continuous efforts of the pioneers who initiated the field of track formation in photographic materials (Corpuscular Photography) and organized the first colloquium on this topic in 1957, the "Colloquia" and "Conferences" on nuclear tracks have evolved into well-established and regular meetings. A key milestone was the foundation of the International Nuclear Track Society (INTS) during the $13^{\text {th }}$ International Conference on Solid State Nuclear Track Detectors held in Rome in 1985. One of the most important tasks of the Society is the sponsorship and organization of International Conferences on Nuclear Tracks in Solids.

\section{Distribution of the number of participants, contributions and papers published during the ten ICNTS meetings from 1990 to 2008}

The total number of papers published in each conference proceedings, from the $15^{\text {th }}$ to the $24^{\text {th }}$ ICNTS, is shown in Figure 1. Figure 1 also shows the number of participants in each conference and the number of presentations given at each conference. The figure clearly shows the variability of the number of papers published per conference: 220 papers were published in the proceedings of the $15^{\text {th }}$ Conference while only 91 were published in the proceedings of the $24^{\text {th }}$ Conference. Conference location is an important determinant of the number of attendants. More researchers and $\mathrm{PhD}$ students from the host country are expected to attend than those from non-host countries. We thus expect conferences held in countries with a greater number of nuclear track workers to record higher attendances. We note that China and India are amongst the most active countries in the field today. The introduction of a more rigorous review process and a reduction in the maximum number of papers to be submitted by each participant has also affected the number of papers published. 
The incorporation of a peer review process has increased the quality of the papers published and was made possible by the remarkable work of two of our colleagues, Prof. Radomir Ilić and Dr. Peter Vater, who organized, improved and polished the rules of the INTS. The more rigorous refereeing process came into effect in 1998. Today, the submission of conference papers is managed in the same way as the submission of non-conference papers to the journal Radiation Measurements.

Figure 2 shows the number of contributions published per participant for each of the ten conferences: this number fluctuates between 0.94 and 1.50. The fluctuation in the number of papers published per participant is consequence both of variations in the number of contributions per participant submitted for publication and of changes to the refereeing process, the latter of course determining the percentage of the papers presented at the conference that are selected for publication. It should be noted that in some cases the author(s) of a contribution decided not to submit the manuscript for publication. However there are other reasons why the number of papers published is generally less than the number of papers presented. One reason is the introduction of new international conferences dealing with topics similar to those covered by the ICNTS meetings. For example, the first SHIM (Swift Heavy Ions in Matter) conference and the first RADECS (Radiation Effects on Components and Systems) conference were both held in 1989, shortly before the $15^{\text {th }}$ ICNTS in 1990 in Marburg, Germany. If we also consider more recent international conferences, such as the NSREC (IEEE Nuclear and Space Radiation Effects Conference, first held in 2006) and the IWSSRR (International Workshop on Space Radiation Research, first held in 2000), it is clear that the observed decrease in both the number of participants and the number of papers published can easily be explained by the appearance of new conferences with overlapping topics. A second reason, internal to the International Nuclear Track Society, and more 
particularly to the Local Organizing Committees, can help to explain the decrease in the number of papers published. Up until and including the 2006 conference, conference organizers allowed each participant to submit up to three abstracts. Beginning in 2008, the maximum number of abstracts to be submitted by each participant was decreased to two. A third reason for the decrease in the number of papers published is related to a change in the requirements of the publisher of the conference proceedings. Up until (and including) 2006, the proceedings book was limited by the publisher to include not more than 1000 pages. In 2008 this limit was substantially reduced to 600 pages. These changes have thus had various effects on the conference proceedings: a reduction in the total number of papers published a reduction in the number of papers published per participant, and an increase in the quality of the papers published.

The distribution of the number of papers published in the conference proceedings (from the $15^{\text {th }}$ to the $24^{\text {th }}$ conference) by original section name is shown in Figure 3 . Three topics stand out: radon measurements (108 papers), nuclear physics (104) and radon (97). These were the only topics about which more than 90 papers were published.

Radon-related topics are the first and third most popular topics in our community, while nuclear physics ranks second. Nuclear physics relies on the remarkable properties of Particle Track Detectors (PTDs) to record single events and to link the geometrical parameters of the etched track to the linear energy transfer (LET) transferred to the surrounding material, or to other fundamental particle-matter interaction properties. The popularity of radon-related topics is likely due to the fact that NTM is the only methodology that allows for the measurement of long-term (several months) radon exposure at a low cost. We now consider those topics about which more than 40 papers were published. 
The following topics fall into that category: Track Development (43); Neutron Measurements (47); Track Formation (63); Dosimetry and Life Science (68); Nuclear Track Physics and Chemistry (60); Methods, Instrumentation and Software (71); High Energy Interactions and Cosmic Rays (70); Earth and Planetary Sciences, Dating (64); Environmental Sciences and Radiometry (54); Radiation-Induced Material Modification (48); and Dosimetry and Radiation Protection (45). These results suggest that all of the papers may be conveniently classified into the following 12 categories: 1) Fundamental mechanisms (track formation, development and observation); 2) Nuclear physics and chemistry; 3) Neutron measurements and analysis; 4) Materials; 5) High-energy and heavy ions; 6) Radon detection and measurements; 7) Environmental (geology) and life sciences; 8) Fission track dating; 9) Dosimetry and other applications; 10) Instrumentation; 11) Cosmic rays and space research; and 12) Nanotechnology. The distribution of the number of publications by category, according to this 12-category classification system, is shown in Figure 4.

Figure 4 shows that the distribution of the number of papers published is much more uniform under this new classification system. The cosmic rays and space research and nanotechnology categories are the two exceptions, showing significantly fewer publications. We note that both of these topics have been the subject of specialized international conferences.

\section{Distribution of the number of papers published during the ten ICNTS meetings from} 1990 to 2008 by category

To explore the evolution of the relative importance of each category, we calculated the categories' relative weight in each conference, that is, the percentage of papers published in 
each category in a given conference with respect to the total number of papers published in that conference. The progression of the relative importance of each category is shown in Figure 5; the mean relative importance and the range are given in Table 1. The following interesting conclusions may be derived from these data:

1.- Certain categories are clearly declining in relative importance. These categories include fundamental mechanisms and cosmic rays and space research. The relative weight of the fundamental mechanisms category exhibits a clear decline from the $15^{\text {th }}$ to the $19^{\text {th }}$ ICNTS meeting, and then stabilizes at less than $5 \%$ of the papers published during the subsequent five conferences. This variation is presumably a natural consequence of Nuclear Track Methodology becoming a mature and well-established technology. Nuclear Track Methodology is no longer a young discipline dominated by research into the fundamental mechanisms of track formation and development. There is currently a reasonable understanding of these processes, although some fundamental research remains necessary. Even though observation methods, particularly following the invention of atomic force microscopy (AFM) in 1986 (Binnig et al., 1986), have evolved over the last few decades, it is clear that most of the developments and experiments in this specific area have already been carried out. The case of the cosmic rays and space research category is different. The trend of this topic reflects the fact that the use of Nuclear Track Detectors in balloon and satellite experiments seeking to determine the composition of cosmic rays was partially improved with the inclusion of digital instrumentation and the advent of the Global Positioning System. In addition, several other conferences are devoted specifically to advances in this area. Finally, we note that the use of NTM within this field of research has seen a recent increase in interest due to the use of new chemical compositions in detectors (see, for example, Kodaira et al., 2009). 
2.- The relative weights of most of the categories fluctuate around the mean value given in Table 1. This information will be useful for the organizers of the next conference because it gives a clear idea of the number of papers to be expected in each category. For example, the nuclear physics and chemistry, neutron measurement and analysis, and instrumentation categories will each contribute approximately $10 \%$ of the total papers published, whereas papers on radon will account for approximately $26 \%$. Further inspection reveals that the neutron measurement and analysis and high energy and heavy ions categories have quasiconstant contributions, indicating a probably long life for these subjects. The other categories exhibit similar behavior. Perhaps it can be highlighted that there was an increase in the relative weight of the Instrumentation category and a decrease in relative weight of the Radon category in the $24^{\text {th }}$ conference. Certainly, there is a feeling among the authors and the Executive Committee of the International Nuclear Track Society that the number of radon papers will decrease in future conferences. This feeling stems from the fact that a paper presenting a radon survey in a city or small area performed with Nuclear Track Detectors and including only the descriptive statistics is no longer an interesting submission for a scientific journal (Font, 2009). Unfortunately, a high percentage of the contributions in this category presented during the last few conferences were not of sufficient scientific interest to be published after the refereeing process.

3.- Nanotechnology, a relatively new application of nuclear track methodology, is gradually becoming more important. The probable increase in the relative weight of this category in forthcoming conferences should be taken into account by future conference organizers. 


\section{Conclusion}

One of the main points noted in this review concerns the variation in the total number of papers published in the conference proceedings over time. It is clear that this phenomenon constitutes an important warning to the International Nuclear Track Society. The identification of the sources of the weakened publication activity should be a priority for the society. There are indeed several reasons why a variation in the number of papers published occurred; we believe that most of these reasons have been identified and described in this paper. It is important to note that the number of publications is a subjective measure of the health of the INTS, and should certainly not be used as the sole indicator of the health of the society. The appearance of international conferences which compete to some extent with those of the International Nuclear Track Society has reduced participation in our conferences. Conference participation is also strongly affected by the location of the conference; geographical distance to countries that are most active in our field is particularly important. Conferences held in countries with important numbers of nuclear track researchers (such as China, India and Russia) record high attendances. The impact factor of the journal Radiation Measurements (5-year impact factor of 1.455; impact factor of 1.177 for the year 2011) has grown over the past few decades, and there has been a consequent increase in the rigor of its review process. An additional point to consider is the fact that many of the pioneers in this field have either retired or passed away. These factors indicate that the topics studied within our community should be strengthened and renewed. If we wish to remain competitive, it is necessary to attract young scientists and to develop a highly productive scientific environment. To attain this goal, our society must remain open to changes, and our members must not hesitate to use their knowledge of nuclear track physics to solve new problems. There are potential applications of our well-developed and improved techniques in several 
research fields, including radiobiology, hadron-therapy and, of course, nanotechnologies. However, as it has been ever since the birth of our community, the future of the INTS is in our hands.

\section{Acknowledgments}

The authors wish to thank A.C. Chavarria and J.I. Golzarri for their technical help. This work was partially supported by PAPIIT-DGAPA-UNAM Project 1N101910.

\section{References}

Binnig G., Quate C. F., Gerber Ch., 1986. Atomic force microscope. Phys. Rev. Lett., 56 (9), 930.

Brandt, R., Spohr, R., Vater, P., 1991. Proceedings of the $15^{\text {th }}$ International Conference on Particle Tracks in Solids. Nuclear Tracks and Radiation Measurements. 19 (1-4), 1974.

Chambaudet, A., Fromm, M., Ilic, R., Vater, P., Dubors, C., Rebetez, M., 1999. Proceedings of the $19^{\text {th }}$ International Conference on Nuclear Tracks in Solids. Radiat. Meas. 31 (16), 1-724.

D'Errico, F., Cecchini, S., Font, L1., Patrizii, L., 2009. Proceedings of the $24^{\text {th }}$ International Conference on Nuclear Tracks in Solids. Radiat. Meas. 44 (9-10), 701-1133.

Dwivedi, K.K., Ilic, R., Vater, P., 2003. Proceedings of the $21^{\text {th }}$ International Conference on Nuclear Tracks in Solids. Radiat. Meas. 36 (1-6), 1-766.

Espinosa, G. (1991). Past, present and future of materials, methodology and instrumentation in Particle Tracks in Solids. Nucl. Tracks Radiat. Meas. 19, 843-846.

Fernandez, F., Ilic, R., Font, Ll., Domingo, C., 2005. Proceedings of the $22^{\text {th }}$ International Conference on Nuclear Tracks in Solids. Radiat. Meas. 40 (2-6), 125-793.

Fleisher, R.L., 1991. Where are Nuclear Tracks leading?, Directions in track studies. Nucl. Tracks Radiat. Meas. 19, 847-854.

Fleisher, R.L., Price, P.B., Walker, R.M., 1975. Nuclear Tracks in Solids (Principles and applications). University of California Press.

Font, L1., 2009. On radon surveys, design and data interpretation. Radiat. Meas. 44, 964-968.

Guo, S.L., Zhao, C.D., Sun, H., 1993. Proceedings of the $16^{\text {th }}$ International Conference on Nuclear Tracks in Solids. Nucl. Tracks Radiat. Meas. 22 (1-4), 1-945. 
Guo, S.L., Font, Ll., Zhang, D., Wang, Y., 2008. Proceedings of the $23^{\text {th }}$ International Conference on Nuclear Tracks in Solids. Radiat. Meas. 43 (1), S1-S664.

Ilic, R., Vater, P., Kenawy, M.A. (1997). Proceedings of the $18^{\text {th }}$ International Conference on Nuclear Tracks in Solids. Radiat. Meas. 28 (1-6), 1-856.

Ilic, R., Jencic, J., Vater, P. (2001). Proceedings of the $20^{\text {th }}$ International Conference on Nuclear Tracks in Solids. Radiat. Meas. 34 (1-6), 1-628.

Kodaira S., Yasuda N., Kawashima H., Kurano M., Hasebe N., Doke T., Ota S., Tsuruta T., Hasegawa H., Sakai S., Nishi T. and Ogura K. 2009. Characteristics of the copolymerized CR-39/DAP track detector for the observation of ultra heavy nuclei in galactic cosmic rays. Radiat. Meas. 44, 775-778.

Perelygin, V.P., Vater, P., Ilic, R., Durrani, S.A. (1995). Proceedings of the $17^{\text {th }}$ International Conference on Nuclear Tracks in Solids. Radiat. Meas. 25 (1-4), 1-776.

Price, P.B., Walker, R.M. (1962). Chemical etching of charged particle tracks. J. Appl. Phys. 33, 3407-3412.

Tommasino, L., Zapparoli, G., Griffith RV., 1980a. Electrochemical etching.1. Mechanisms. Nucl. Tracks Radiat. Meas. 4 (3), 191-196.

Tommasino, L., Zapparoli, G., Griffith RV., 1980b. Electrochemical etching.2. Methods, apparatus and results. Nucl. Tracks Radiat. Meas. 4 (3), 197-201.

Young, D.A., 1958. Etching of radiation damage in lithium fluoride. Nature, 182, 375-377. 